\title{
Desempenho de oito variedades de soja na várzea do rio Solimöes, na ilha da Paciência, no periodo agrícola de 1976-1977
}

\author{
Fazal Rahman (")
}

Resumo

Oito variedades de soja do Instituto de Agricultura Tropical da Nigéria (IITA) foram testadas no Amazonas, acrescentando germoplasma valioso à soja que foi anteriormente plantıda, na várzea, em programas de melhoramento. Uma das caracterís. ticas dessas variedades é a insensibilidade fotoperiódica e a alta produtividade em ambientes tropicais. O máximo rendimento obtido neste experimento foi de $1145 \mathrm{~kg}$ por hectare pela variedade TGM 256-1-B. Devido terem sido plantadas a 24-11-1976, as variedades ficaram expostas a condiçōes climáticas extremamente desfavoráveis durante os estágios críticos de crescimento. Muitas linhagens apresentaram excelentes características fotoperiódicas que, sem dúvida alguma, terão uso prático em futuros programas de melhoramento. A nodu. lação foi relativemente pobre e a qualidade das sementes, na maioria dos casos, foi consideravelmente reduzida. Para uma avaliaçäo justa dessas linhagens, é necessário que o plantio seja feito logo após a descida do nível da água na várzea (agosto setembro).

\section{INTRODUÇÃo}

Oito variedades de soja do Instituto Internacional de Agricultura Tropical (IITA), foram cultivadas especificamente para testar sua resistência às condiçōes tropicais prevalentes no Amazonas. Como a soja só foi introduzida recentemente na Amazônia é imprescindivel a construção de um banco de germoplasma e a realização de seleções extensivas das características úteis para futuros programas de meIhoramento.

\section{MATERIAIS E MÉTODOS}

O modelo experimental foi o de blocos totalmente casualizados, nos quais cada uma das 8 variedades foi replicada 4 vezes em canteiros de 4 linhas de 5 metros de comprimento cada. A distância entre as linhas foi de $60 \mathrm{~cm}$ e entre as plantas de $5 \mathrm{~cm}$. Somente as duas fileiras centrais foram utilizadas para coleta de dados, exceto no caso de nodulação, em que 10 plantas foram arrancadas em duas datas diferentes (na época do florescimento e 3 semanas mais tarde).

As análises de solo, realizadas nos laboratórios da EMBRAPA, indicaram um pH de 4,8 e uma proporção de $0,17 \% \mathrm{~N}, 1,4 \% \mathrm{C}, 17 \mathrm{ppm}$ $\mathrm{P}, \mathrm{Ca}+\mathrm{Mg}$ me $\% 18,6$, Al me \% 1,3. Os fertilizantes foram aplicados na proporção de 25 $\mathrm{kg}$ de $\mathrm{N}, 25 \mathrm{~kg}$ de $\mathrm{P}, 25 \mathrm{~kg}$ de $\mathrm{K}$ e $2.000 \mathrm{~kg}$ de calcário por hectare. As sementes foram inoculadas com Rhizobium japonicum. Os inseticidas Malathion e Azodrin foram aplicados de tempos em tempos para controle de alguns insetos.

O experimento foi plantado em 24 de novembro de 1976. Plantio, colheita e debulha das sementes foram feitos manualmente.

As variedades incluídas no experimento foram: TGM 256-1-B, TGM 294-4-2371, TGM 220-1-2205, TGM 255-2-4341, TGM 249-4-B, TGX 066-5100, TGM 210-1-2363, TGX 13-3-2644 (controle).

Foram coletados dados sobre produçăo, número de dias requericios para florescimento $\mathrm{e}$ maturidade, número de nódulos, peso seco dos nódulos (os nódulos foram desidratados a $70^{\circ} \mathrm{C}$ por 24 horas), altura da planta, acamamento, deiscência, número de plantas colhidas, número de vagens por planta, peso de 100 sementes, qualidade das sementes e índice de doenças. Os dados foram analisados em computador e com metodologia estatística adequada para análise de variância. Foi empregado o teste LSD para comparação dos níveis de significância das diferenças entre as médias. A precipitação mais alta registrada durante o experimento foi de $763,5 \mathrm{~mm}$.

$\left({ }^{\bullet}\right)$ - Instituto Nacional de Pesquisas da Amazônia, Manaus. 


\section{RESUltados E DISCUSSÃo}

A Tabela 1 apresenta os dados sobre produção, número de dias requeridos para florescimento e maturidade, número e peso seco dos nódulos, altura da planta, acamamento, deiscência, número de vagens por planta, peso de 100 sementes, qualidade das sementes e índice de doenças.
A produção variou de $302 \mathrm{~kg}$, no caso da variedade TGX 13-3-2644 (segundo Nangju et al. (1975) esta foi uma das duas variedades mais produtivas do IITA, com uma média de $1475 \mathrm{~kg} / \mathrm{ha}$ sob cinco condições ambientais diferentes), a $1145 \mathrm{~kg}$ por hectare, com a variedade TGM 256-1-B. A variedade TGM 294-4-2371 produziu $978 \mathrm{~kg} / \mathrm{ha}$, seguindo de perto a produção mais alta. As diferenças não

TABELA 1 - Comportamento de 8 variedades de soja do IITA-Nigéria, nas várzeas do rio Solimōes, Dados sobre produção, n. ${ }^{\circ}$ de dias requeridos para florescimento e maturidade, número de nódulos, peso seco dos nódulos baseado em 10 plantas colhidas em duas datas (na época de floração e três semanas depois), altura da planta, acamamento, deiscência, número de plantas colhidas, número de vagens por planta, peso de 100 sementes e qualidade das sementes.

\begin{tabular}{|c|c|c|c|c|c|c|c|c|c|c|}
\hline VARIEDADE & $\begin{array}{c}\text { Produção } \\
\text { kg/ha }\end{array}$ & $\begin{array}{l}\text { N. }{ }^{\circ} \text { de dias } \\
\text { do plantio } \\
\text { atè o flo- } \\
\text { rescimento }\end{array}$ & $\begin{array}{c}\text { N. }{ }^{\circ} \text { de dias } \\
\text { do plantio } \\
\text { até a ma- } \\
\text { turidade }\end{array}$ & $\begin{array}{l}\text { N. de nó- } \\
\text { dulos da } \\
\text { 1.a data }\end{array}$ & $\begin{array}{l}\text { N. de nó- } \\
\text { dulos da } \\
2 .^{\mathrm{a}} \text { data }\end{array}$ & $\begin{array}{c}\text { Peso (em } \\
\text { gramas) } \\
\text { dos nódu. } \\
\text { los da 1.a } \\
\text { dota }\end{array}$ & $\begin{array}{l}\text { Peso (em } \\
\text { gramas) } \\
\text { dos nódu- } \\
\text { los da 2.a } \\
\text { data }\end{array}$ & $\begin{array}{c}\text { Altura } \\
\text { (em cm) } \\
\text { da planta }\end{array}$ & $\begin{array}{l}\text { Acama- } \\
\text { mento }=\end{array}$ & $\begin{array}{c}\text { Deiscên- } \\
\text { cia * }\end{array}$ \\
\hline TGM 256-1-B & 1145 & 40.0 & 94.0 & 42.5 & 40.5 & 0.28 & 0.50 & 73 & 1.75 & 1 \\
\hline TGM 294-4-2371 & 978 & 40.8 & 94.0 & 52.8 & 108.3 & 0.30 & 0.62 & 70 & 1.25 & 1 \\
\hline TGM 220-1-2205 & 764 & 42.0 & 110.0 & 28.0 & 51.8 & 0.30 & 0.55 & 58 & 2.75 & 1 \\
\hline TGM 255-2-4341 & 706 & 33.5 & 101.8 & 37.5 & 64.5 & 0.28 & 0.63 & 88 & 2.00 & 1 \\
\hline TGM 249-4-B & 702 & 33.8 & 101.8 & 55.0 & 74.8 & 0.30 & 0.65 & 96 & 1.25 & 1 \\
\hline TGX 66.5100 & 512 & 40.0 & 92.5 & 32.3 & 52.5 & 0.40 & 0.57 & 100 & 2.50 & 1 \\
\hline TGM 210-1-2363 & 382 & 40.0 & 103.0 & 47.8 & 73.0 & 0.25 & 0.52 & 66 & 1.75 & 1 \\
\hline TGX 13-3-2644 & & & & & & & & & & \\
\hline (check) & 302 & 33.8 & 107.0 & 39.0 & 70.0 & 9.25 & 0.78 & 95 & 1.25 & 1 \\
\hline c. V. & $60.93 \%$ & $0.94 \%$ & $1.86 \%$ & $38.69 \%$ & $66.78 \%$ & $38.51 \%$ & $54.29 \%$ & $8.29 \%$ & $23.70 \%$ & \\
\hline $5 \%$ LSD & NS & 0.52 & 2.76 & NS & NS & NS & NS & 9.8 & 0.63 & \\
\hline
\end{tabular}

\begin{tabular}{|c|c|c|c|c|}
\hline Variedade & $\begin{array}{l}\text { Número de } \\
\text { plantas } \\
\text { colhidas }\end{array}$ & $\begin{array}{l}\text { Número de va- } \\
\text { gens por planta } \\
\text { (baseado em } \\
10 \text { plantas) }\end{array}$ & $\begin{array}{l}\text { Peso de } 109 \\
\text { sementes }\end{array}$ & $\begin{array}{l}\text { Qualidade das } \\
\text { sementes } \\
(\forall \mapsto \emptyset)\end{array}$ \\
\hline TGM 256-1-B & 137 & 51 & 11.0 & 3.0 \\
\hline TGM 294-4-2371 & 157 & 42 & 16.4 & 2.5 \\
\hline TGM 220-1 2205 & 135 & 88 & 15.1 & 2.5 \\
\hline TGM $255-2-4341$ & 137 & 96 & 13.4 & 3.5 \\
\hline TGM 249-4-B & 136 & 78 & 17.3 & 3.3 \\
\hline TGX $66-5100$ & 144 & 76 & 14.3 & 2.8 \\
\hline TGM 210-1-2363 & 141 & 51 & 16.9 & 3.5 \\
\hline $\begin{array}{l}\text { TGX 13-3-2644 } \\
\text { (check) }\end{array}$ & 131 & 48 & 19.1 & 3.3 \\
\hline C.V. & $6.83 \%$ & $17.02 \%$ & $8.52 \%$ & $30.89 \%$ \\
\hline L.S.D. & 14.0 & 16.6 & 1.9 & NS \\
\hline
\end{tabular}

(*) - Acamamento $-1=$ nōo acama, $2=$ acama muito pouco, $3=$ acama moderadamente, $4=$ acama bastante, $5=$ proticamente todas as plastas acamam.

(*) - Deiscência - $1=$ ausência de deiscência, $2=10 \%$ de deiscência, $3=10$ a $30 \%$ de deiscência, $4=30$ a $50 \%$ de deiscềncio, $5=$ mais de $50 \%$ de deiscència.

$(\cdots)$ - Qualidale $-1=$ excelente, $2=$ bom, $3=$ regular, $4=$ pobre, $5=$ muito pobre. 


\begin{tabular}{l|c|c}
\hline & \multicolumn{2}{|c}{ Contagem da doença (") } \\
\cline { 2 - 3 } \multicolumn{1}{c}{ Variedade } & $\begin{array}{c}\text { Vírus do mo- } \\
\text { saico da soja } \\
\text { (SMV) }\end{array}$ & $\begin{array}{c}\text { Mancha } \\
\text { vermelha }\end{array}$ \\
& & \\
\hline TGM 256-1-B & 1.75 & 1.00 \\
TGM 294-4-2371 & 1.75 & 2.25 \\
IGM 220-1-2205 & 1.75 & 2.00 \\
TGM 255-2-4341 & 1.75 & 2.25 \\
TGM 249-4-B & 1.25 & 2.00 \\
TGX 66-5100 & 1.75 & 2.00 \\
TGM 210-1-2363 & 1.25 & 2.75 \\
IGX 13-3-2644 & 2.00 & 1.75 \\
& & \\
\hline
\end{tabular}

(*) Média de 4 replicaçōes:

Indice de doença $-1=$ sem sintomas, $2=$ leves sin-

tomas; poucas plantas ou sementes afetados, $3=\sin$ -

tomas moderodos; um número cons.derável de plantas

afetados, $4=$ sintomas severos; muitas plantas atetadas,

$5=$ sintomas severos em quase todas as plantas.

são estatisticamente significativas. As principais razōes para as produções relativamente vaixas do presente experimento foram o plantio tardio, que fez com que as plantas ficassem expostas a chuvas excessivas durante estágios críticos de crescimento e maturidade, e a nodulação relativamente pobre.

A amplitude do tempo necessário para florescimento e maturidade variou entre 33,5 e 42 dias e 92,5 e 110 dias, respectivamente. A variedade que floresceu primeiro foi TGM 255-2-4341, e por último foi TGM 220-1-2205, que também demandou o mais longo periodo ae maturidade. A variedade TGM 256-1-B, que produziu a maior colheita, necessitou de 40 dias para florescer e de 94 dias para maturar. Algumas das linhagens foram criadas especialmente para serem insensiveis ao fotoperiodismo. Elas devem ser plantadas mais cedo e tes. tadas sob condições mais favoráveis ao crescimento para que seus desempenhos possam. ser avaliados. Além disso, a insensibilidade genética ao fotoperiodismo que apresentam pode ter uso prático no melhoramento de outros genótios altamente convenientes que carecem dessa característica.

$\mathrm{O}$ número e o peso dos nódulos, com base na média de 10 plantas, variaram entre 28 e 55 e 0,25 gramas e 0,40 gramas, respectiva- mente, enquanto que os resultados obtidos na segunda coleta indicaram um número variando de 40,5 a 108,3 e um peso de 0,50 gramas a 0,78 gramas. Todas essas diferenças năo săo estatisticamente significativas.

A variedade que mais cresceu foi TGX 66-5100, alcançando até $100 \mathrm{~cm}$ de altura, enquanto que a mais baixa foi TGM 220-1-2205. com $58 \mathrm{~cm}$. Ambas acamaram moderadamente. Não foi observada deiscência durante o experimento. O númera de vagens por planta variou de 42 a 96 enquanto que o peso de 100 sementes variou de 11,0 a 19,1 gramas. $\mathrm{Na}$ maioria das variedades a qualidade das sementes foi reduzida consideravelmente, conforme indicam as avaliações na Tabela 1. Foi observada a ocorrência do Vírus do Mosáico da Soja (SMV), de Manchas Vermelhas e de Pústula Bacteriana. As variedades TGM 249-4-B e TGM 210-1-2363 apresentaram boa resistência ao SMV enquanto que a variedade TGM 256-1-B foi bastante resistente à Mancha Vermelha .

\section{SUMMARY}

Eight varieties of soybean ibtained from the Tropical Agriculture Institute of Nigeria (IITA) were tested in Amazonas thus increasing this valuable germplasm collection to soybean previously planted in the varzea in other yrograms. One of the characteristics of these varieties is insensitivity to photoperiod and high productivity in tropical environments. The maximum yield obtained in this experiment was $1145 \mathrm{~kg} /$ hectare with variety TGM 256-1-B. Having been planted on the $24^{\text {th }}$ of November of 1976, these varieties were exposed to extremely disfavorable climatic conditions during the critical stages of development. Many of the lineages presented excellent photoperiod characteristic which will undoubtedly have great use in future bettering programs. Nodulation was relatively poor, and the quality of seeds was, in most cases, greatly reduced. For a just avaliation of these lineages, it is necessary to plant as soon as the water level descends in varzea (AugustSeptember).

\section{BIBLIOGRAFIA}

NANGJU, D.; RAChIE, K.O.; WATt, I.E. \& SiNGH, T.P. 1975 - Cowpea and Soybean Uniform Cultivar Trials. Summary of results. IITA/GLIP Publication. Received in 1977.

(Aceito para publicação em 17/02/78) 